\title{
Important Elements and Features of Neighborhood Landscape for Aging in Place: A Study in Hong Kong
}

\author{
Shu-Lin Shi* \\ Department of Landscape Architecture, School of Architecture, Tsinghua University, Beijing, China
}

\section{OPEN ACCESS}

Edited by:

Zhonghua Gou,

Griffith University, Australia

Reviewed by:

Yiqi Tao,

Shenzhen University, China

Xuechen Gui,

Griffith University, Australia

Yiyong Chen,

Shenzhen University, China

*Correspondence:

Shu-Lin Sh

shishulin@tsinghua.edu.cn;

sprucysky@hotmail.com

Specialty section:

This article was submitted to

Environmental Health,

a section of the journal

Frontiers in Public Health

Received: 13 March 2020

Accepted: 09 June 2020

Published: 17 August 2020

Citation:

Shi SL (2020) Important Elements and Features of Neighborhood Landscape for Aging in Place: A Study in

Hong Kong.

Front. Public Health 8:316

doi: 10.3389/fpubh.2020.00316
With rapid growth in the aging population around the world, the promotion of aging in place has become more significant in recent years. Many neighborhood landscape elements and features have been revealed by accumulating research findings to be critical to aging in place. However, they are usually studied separately or in small groups. Little has been done to examine the relative importance of these elements and features when brought together, from the older adult's point of view. In this context, the current study investigated the perceived importance for older adults of 22 selected neighborhood landscape elements and features. A questionnaire survey was conducted in 17 public rental housing estates in Hong Kong with proportions of older residents (aged 65 or above) between 20 and $40 \%$. According to the 426 collected samples, older adults considered as highly important landscape elements and features that contribute to comfort and help them avoid hazards, such as good ventilation, protection from severe sunshine/rain, body support, and good hygiene, while elements were thought to potentially bring hazards while not being necessities for older adults' outdoor experience were considered least important, including portable chairs, outdoor tables, plants that can be touched, closeness to children's playgrounds, small spaces for solitude, water features, and fitness equipment. After integrally interpreting the findings regarding perceived importance with other collected data, some landscape design suggestions are generated to supplement existing guidelines and recommendations concerning older adults' well-being and quality of life. These findings can inspire future research and landscape design that prioritize promoting aging in place.

Keywords: neighborhood, landscape elements and features, perceived importance, older adults, aging in place

\section{INTRODUCTION}

The world's population is aging rapidly. In 2019, about 9\% of the global population was aged 65 or above. This proportion is estimated to reach $12 \%$ by 2030 and $16 \%$ by 2050 . Furthermore, projections indicate that the population of aged people will be twice as many as that of children aged 0-4 and will exceed youths aged 5-14 and 15-24, respectively, by 2050 (1). Although an aging population places increasing demands on caring for older adults, it does not make sense to institutionalize them all. In fact, most older adults would prefer not to leave communities that they are familiar with (2). Considering the decaying health condition of most older adults, outdoor space near their residences would play an important role in promoting aging in place, i.e., to support them in living independently in their neighborhoods and homes for as long as possible. 
Since the 2000s, there has been a sharp increase in research in this field (3). On the one hand, functional and cognitive impairment, chronic diseases, a diminishing social network, and a low level of physical activities have been identified as hindered aging in place (4-7). On the other hand, neighborhood outdoor environments have been revealed as better for older adults' wellbeing through helping retain their preferred lifestyles, social connections, and sense of control, together with better clinical outcomes compared with their institutionalized counterparts (8). If an environment is enjoyable, and hence induces enjoyable activities inside it, it would contribute to users' quality of life $(9,10)$. In such relatively small-scale outdoor environments, landscape elements, and features can be closely experienced and thus be critical for promoting aging in place.

\section{OUTDOOR LANDSCAPES FOR OLDER ADULTS}

According to mounting research findings, outdoor spaces, especially those with natural elements, have been broadly proven to be contributive to older adults' physical, mental, and social well-being and to further enhance their quality of life (1115). Actually, once they have stepped into nature, older adults may immediately feel relieved, away from the indoor sources of depression (16). In most cases, the neighborhood outdoor landscape contains natural elements such as plants and water and likely attracts small animals. These are good sources of various sensory stimulations. According to Cox et al. (17), less sadness is experienced when being in a garden or a place with sensory stimulations than when indoors. Even for individuals with dementia, their psychological symptoms decrease after accessing a natural setting (18). If the landscape is properly designed and equipped with facilities, it can encourage physical activities that can sustain and even improve the physical and mental health of older adults (19). In many cases, simply walkable green spaces near residences can positively influence the longevity of older adults in urban areas (20). In addition, inter-personal interactions and activities in the outdoor spaces can provide social support to older adults, thus fostering a sense of belonging or community that can be good for their well-being as well (21).

Although simply viewing a landscape with natural elements is already contributive to human beings' well-being (22-24), there will be much greater well-being benefits and a richer experience when a person is physically in a space with landscape design. Therefore, accessibility and safety should be ensured first to support older adults with declining health conditions $(25,26)$. Accessibility generally refers to the availability of spaces and certain facilities, connectivity with destinations, and barrierfree design solutions (27). Safety mainly concerns crimes and accidents while using outdoor spaces $(28,29)$.

Aside from such fundamental factors, landscape design elements have also been discussed in responding to older adults' specific needs. For instance, with reduced strength and stamina, older adults may not be able to walk as far or as fast as younger ones. Correspondingly, they need more resting facilities, shelters, and shade where they can take rests and be protected from unfavorable weather conditions (10). They may also have difficulties in keeping good balance and thus need handrails or other facilities as support (30). Furthermore, many older adults have deteriorated eyesight or visual impairments. This, together with reduced balance, make it easy for them to fall and get hurt due to unleveled pavements, illusions of level changes due to shadows or different colors of paving materials, or glare from paving materials (30). In addition, life after retirement usually makes older adults feel bored, and they need some interests in life or to engage in social activities (31). In supporting these needs, ornamental plants can not only provide sensory stimulations and enjoyments but can also trigger certain interactions between people, thus enhancing social networking $(10,32)$. People moving around and children playing in a neighborhood also effectively add liveliness to the spaces. Older adults commonly like to watch these people, and may incidentally meet friends, which also contributes to their quality of life (33). Besides, if outdoor space design could provide older adults with more of a sense of control and choice, they would get more satisfaction. For instance, portable chairs that allow people to sit in the positions and orientations they like, tables that provide support for food and drinks or reading, and different paths to take could be included (30).

Based on a growing body of evidence, design guidelines on outdoor landscapes for older adults have emerged. Most guidelines cover the above-mentioned design aspects and provide practical recommendations $(30,34,35)$. However, with the constraints of site conditions and available resources for each project, it can be very challenging to meet all design requirements or recommendations in practice, except for some fundamental requirements like barrier-free design, leveled pavements, and sufficient lighting. Usually, it is also hard to judge which landscape elements and features are more important, as most of them are studied separately by different researchers and with different research methodologies. These may hinder the utilization and well-being benefits of landscape $(36,37)$. The above review implies that older adults' concerns related to community landscape design should be studied comprehensively. For instance, when different landscape elements and features are put together, which of them are more important for older adults? Therefore, this study was conducted to investigate the perceived relative importance of landscape elements and features in the eyes of older adults, focusing on neighborhood outdoor landscapes, with the hope of supporting landscape research and design that aims to promote aging in place.

\section{METHODOLOGY}

\section{Hong Kong Situation}

The study was conducted in Hong Kong, a city facing serious aging problems, like many other cities in the world. According to the Census and Statistics Department of the HKSAR government, the proportion of people aged 65 and above reached $17.0 \%$ of the entire population in mid-2018 (38), and it is expected to reach $31.1 \%$ (2.37 million in total) by 2036 and $36.6 \%$ (2.59 million) in 2066 (39). As revealed by a government survey, older adults in Hong Kong would like to age at home and live in a familiar 
TABLE 1 | Basic information of 17 selected PRH estates.

\begin{tabular}{|c|c|c|c|c|c|c|}
\hline No. & Authorized party & Name of estate & $\begin{array}{l}\text { Year of intake } \\
\text { (establishment) }\end{array}$ & $\begin{array}{c}\text { Population aged } 65 \\
\text { and above* }\end{array}$ & $\begin{array}{c}\text { Total } \\
\text { population* }\end{array}$ & $\begin{array}{l}\% \text { of aged } \\
\text { residents }\end{array}$ \\
\hline 1 & $\mathrm{HA}$ & Shui Pin Wai Estate & 1981 & 2,691 & 6,725 & 40.0 \\
\hline 3 & $\mathrm{HA}$ & Lok Wah South Estate & 1982 & 4,452 & 12,843 & 34.7 \\
\hline 4 & $\mathrm{HA}$ & Lai Kok Estate & 1981 & 2,224 & 6,488 & 34.3 \\
\hline 7 & $\mathrm{HA}$ & Fuk Loi Estate & 1963 & 2,260 & 6,999 & 32.3 \\
\hline 8 & $\mathrm{HA}$ & Sha Kok Estate & 1980 & 4,384 & 14,522 & 30.2 \\
\hline 9 & $\mathrm{HA}$ & Cheung Sha Wan Estate & 2013 & 800 & 3,344 & 23.9 \\
\hline 10 & $\mathrm{HA}$ & Hung Hom Estate & $1999 / 2011$ & 1,553 & 6,623 & 23.5 \\
\hline 11 & $\mathrm{HA}$ & Oi Tung Estate & 2001 & 2,254 & 8,028 & 28.1 \\
\hline 15 & $\mathrm{HA}$ & Lai On Estate & 1993 & 715 & 2,957 & 24.2 \\
\hline 16 & $\mathrm{HA}$ & Ko Yee Estate & 1994 & 761 & 3,326 & 22.9 \\
\hline 17 & HS & Ka Wai Chuen & 1984/87/90/93 & 1,511 & 6,928 & 21.8 \\
\hline
\end{tabular}

${ }^{*}$ According to population census 2016 (44).

community until they need residential care services: $96.4 \%$ of 1,130 elderly participants did not intend to move into a local residential elderly care facility (40). This is supported by findings of a more recent survey in Hong Kong (41).

With the dense and compact development mode in Hong Kong, outdoor spaces within residential estates are critical for aging in place and the well-being of older adults, as most of them are traffic-free. Among different types of residential developments in Hong Kong, public rental housing (PRH) estates developed by the Hong Kong Housing Authority (HA) and the Hong Kong Housing Society (HS) always provide such spaces at a relatively sufficient proportion of the total site area. Meanwhile, the HA and HS are also major providers of rental housing for senior citizens in Hong Kong. According to the 2016 Population By-census, among the 2,100,126 total population living in $\mathrm{PRH}, 392,575$ (18.7\%) were older adults aged 65 or above, comprising $36.7 \%$ of all elderly people in domestic households in Hong Kong (42). The HA and HS's role in supporting the aging population will become more critical in future, and so will outdoor landscape design in PRH estates.

\section{Estate Selection}

Among the 199 PRH estates in Hong Kong (190 developed by the HA and 9 by the HS), most open spaces were developed in similar ways, except for accommodating fewer water features in recent years and some style evolutions on plant species selection (43). In this study, $17 \mathrm{PRH}$ estates were selected, mainly based on the proportion of aged residents and forward-looking considerations: eight with 30-40\% aged people among residents, representing an overall population scenario in the next halfcentury or even a longer period, and the remaining nine with 20 $30 \%$ aged people among residents to represent a scenario of the near future (Table 1). The distribution of these estates is shown in Figure 1. Examples of typical landscape elements and features in these estates are shown in Figure 2.

\section{Questionnaire Design}

A questionnaire was designed to collect data mainly about perceived importance for a set of landscape elements and features in neighborhood outdoor spaces. The landscape elements and features were extracted from various design guidelines and published studies concerning outdoor landscape elements and features for aged people, while those already commonly agreed as fundamental and that have been incorporated in $\mathrm{PRH}$ estates, such as barrier-free accessibility and a non-slippery ground surface, were excluded. Each of the 22 final listed items' association with the well-being and quality of life of aged people has been identified or proven by empirical studies. These landscape elements and features were categorized into Convenience, Comfort, Sense of safety, Sense of control, Stimulation, and Social support to facilitate discussion (Table 2).

Specifically, Convenience covers two sub-categories, namely, supportive distance, and supporting elements. Supportive distance mainly concerns the distance between major destinations and facilities that older adults would need to visit, e.g., shops and public toilets; together with allocation of neighborhood outdoor spaces, i.e., the distance between spaces and major pedestrian routes $(45,46,49,50)$. Supporting elements refers to those that have been shown by some studies to help older adults keep their body balance and avoid falling (51). 


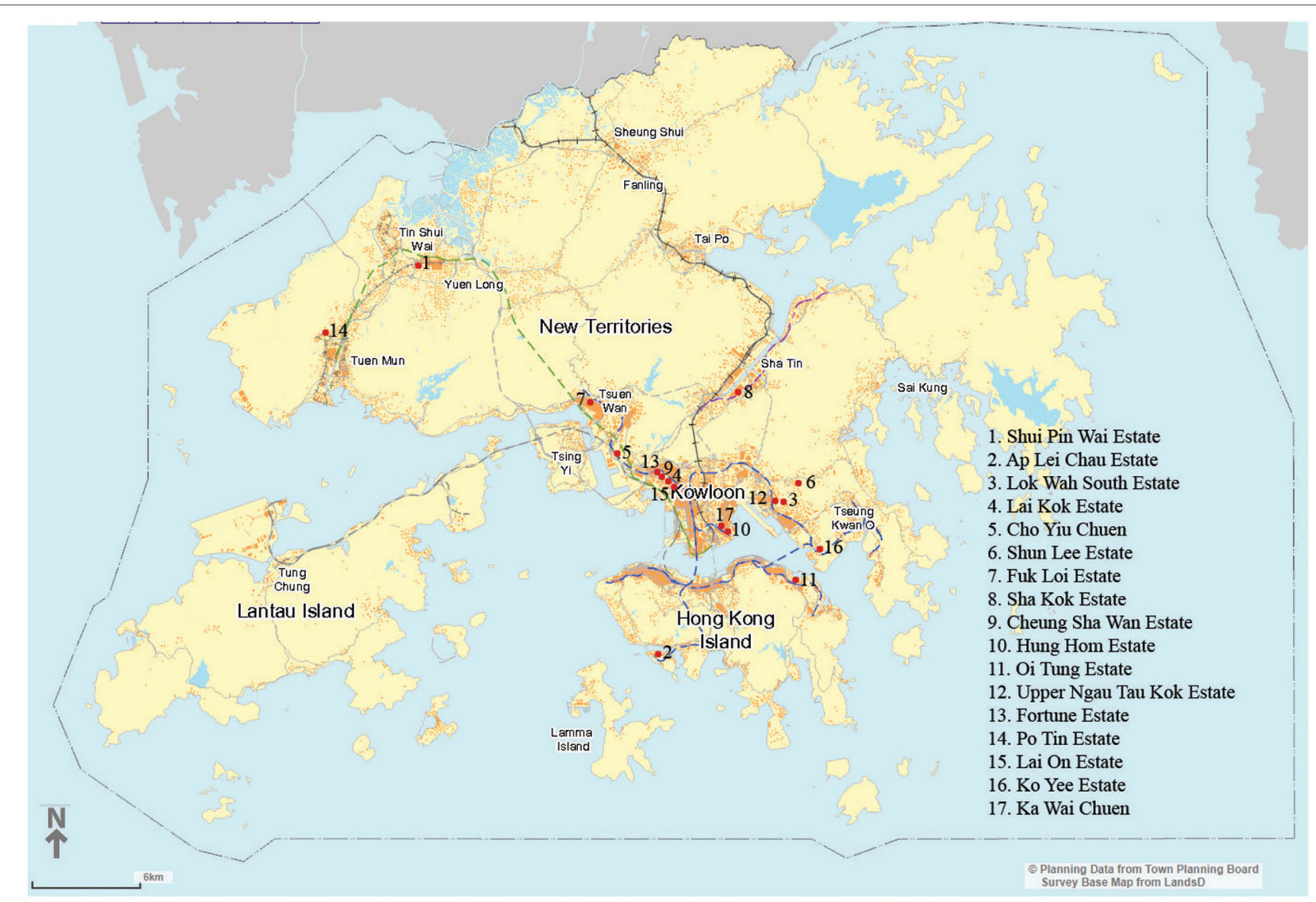

FIGURE 1 | Distribution of selected PRH estates (Source of base map: https://www1.ozp.tpb.gov.hk/gos/default.aspx).

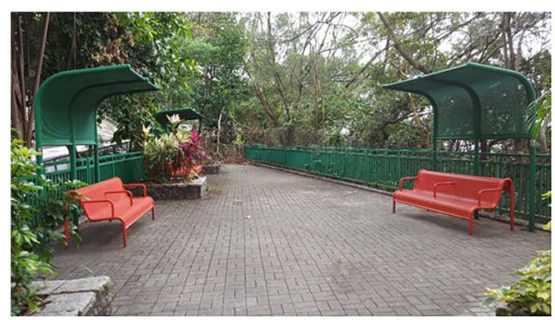

Small space

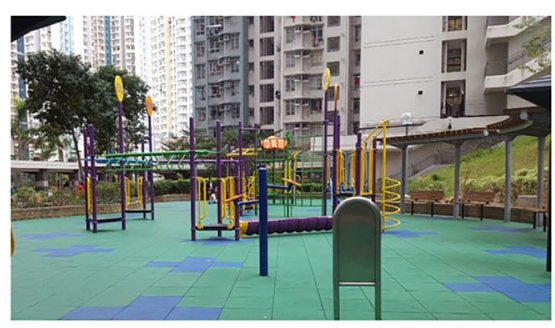

Children's playground

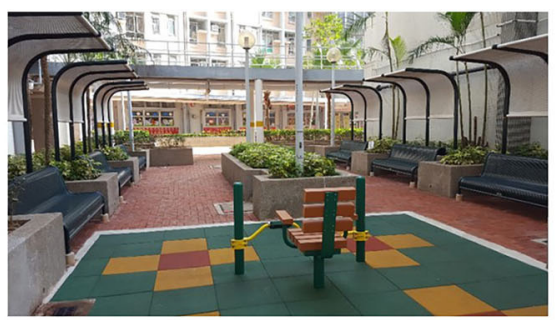

Medium space

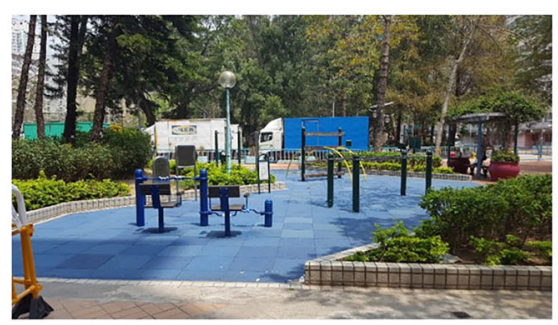

Fitness area

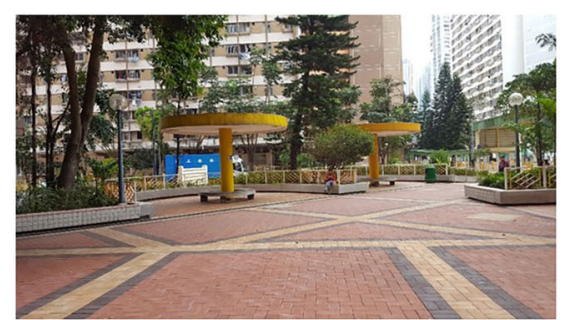

Large space

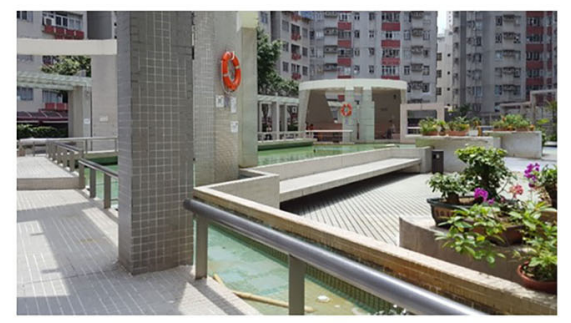

Water feature

FIGURE 2 | Typical landscape elements and features in selected PRH estates (photoed by author). 
TABLE 2 | Selected landscape elements and features.

\begin{tabular}{|c|c|c|c|}
\hline Category & Sub-category & Landscape elements/features in questionnaire & $\begin{array}{l}\text { Studies on health influence \& } \\
\text { design guidelines of } \\
\text { landscape element/feature }\end{array}$ \\
\hline \multirow[t]{9}{*}{ Convenience } & Supportive distance & Close to major pedestrian route & $(45)$ \\
\hline & & Close to shops (convenient purchase of food and drinks) & $(46)$ \\
\hline & & & $(47)$ \\
\hline & & & $(48)$ \\
\hline & & & (49) \\
\hline & & & $(50)$ \\
\hline & & Close to public toilet & $(10,12)$ \\
\hline & Supporting elements & Body support (bench, planter edge, railing, etc.) & $\begin{array}{l}(51) \\
(30)\end{array}$ \\
\hline & & Outdoor table (independent or attached to a bench) & $(30)$ \\
\hline \multirow[t]{3}{*}{ Comfort } & $\begin{array}{l}\text { Weather-related } \\
\text { solutions }\end{array}$ & Avoidance of severe sunshine/rain & $\begin{array}{l}(10) \\
(52)\end{array}$ \\
\hline & & Good ventilation & (49) \\
\hline & Hygiene & Good hygiene & $(49)$ \\
\hline \multirow[t]{3}{*}{ Sense of safety } & - & $\begin{array}{l}\text { Can see what is happening from outside } \\
\text { (to decide whether to enter or not, timely emergency } \\
\text { treatment, etc.) }\end{array}$ & $(37)$ \\
\hline & & Can see what is happening nearby & $(37)$ \\
\hline & & Quiet environment & (49) \\
\hline \multirow[t]{3}{*}{ Sense of control } & Privacy & Small space for solitude & $\begin{array}{l}(30) \\
(53)\end{array}$ \\
\hline & Have choices & Multiple entrances/exits for a space & $(30)$ \\
\hline & & Portable chair & $\begin{array}{l}(30) \\
(53)\end{array}$ \\
\hline \multirow[t]{6}{*}{ Stimulation } & Sensory stimulation & $\begin{array}{l}\text { Open view (can see distant plants, buildings, mountains, } \\
\text { etc.) }\end{array}$ & $\begin{array}{l}(30) \\
(53)\end{array}$ \\
\hline & & Water feature (pool or water fountain, etc.) & $\begin{array}{l}(30) \\
(53)\end{array}$ \\
\hline & & Ornamental plants & $\begin{array}{l}(27) \\
(10) \\
(54) \\
(32)\end{array}$ \\
\hline & & Plants that can be touched & $\begin{array}{l}(30) \\
(55)\end{array}$ \\
\hline & & $\begin{array}{l}\text { Visible dynamic elements (e.g., activities of other people, } \\
\text { people/vehicles passing by, small animals, dynamic } \\
\text { water, water fountain, plants moving in the wind, etc.) }\end{array}$ & (30) \\
\hline & Exercise stimulation & Fitness equipment & $\begin{array}{l}(19) \\
(56) \\
(49)\end{array}$ \\
\hline \multirow[t]{2}{*}{ Social support } & - & Large space for gathering & $\begin{array}{l}(57) \\
(49)\end{array}$ \\
\hline & & Close to children's playground & $(10)$ \\
\hline
\end{tabular}

However, in Hong Kong, older adults tend to equip themselves with canes, walkers, and wheelchairs to avoid potential falls. Hence, supporting elements in this study refers to body support, like benches, planter edges, and railings, or elements like outdoor tables that help relieve users' burden $(30,51)$.

Comfort covers aspects of weather-related solutions and hygiene. The sub-tropical climate in Hong Kong makes it hot and humid, with a lot of showers, during long summers. Therefore, elements that can protect people from severe sunshine/rain and spaces with good ventilation (air flow) are critical to enable people to stay outside $(10,49,52)$. In addition, hygiene would also affect people's comfort through visual and osphretic aspects (49). Poor hygiene conditions may also spread germs and affect the health of vulnerable older adults. This is also a concern of older PRH residents (41).

Regarding Sense of safety, it is generally quite safe in PRH estates, as security guards patrol frequently and CCTV covers all public areas. Therefore, safety in this study is mainly about 
whether older adults can receive instant help in case of accident and whether they are forewarned of potential hazards. Under such circumstances, the in-outward visual connections of a space could be critical (37). Besides, quiet environments can lower the alert level and make people feel safe and relaxed (49). Although it is arguable that people may feel upset in a completely quiet environment, such a case seldom exists in outdoor spaces in developed areas in Hong Kong due to its high population density.

Research has found that older adults with a higher sense of control usually enjoy better health (58). Therefore, it would be good if outdoor landscapes could provide a certain extent of privacy by creating small spaces where one or two people could stay alone and away from disturbances $(30,53)$. Besides, providing different route choices to a space can also enhance the sense of control (30). In addition, portable chairs are also considered contributive to sense of control, as discussed above $(30,53)$.

The category of Stimulation covers sensory and exercise stimulations in this study. Sensory stimulations include landscape elements and features like open views, water features, ornamental plants, plants that can be touched, and visible dynamic elements (10, 27, 30, 32, 53). Among these, touching plants has been proven to be soothing and therapeutic (55). However, to prevent mosquito problems, most landscape property managements apply pesticides on plants and warn people about this with signage boards in Hong Kong. Therefore, Hong Kong people tend not to touch plants in reality. Nonetheless, behavior may not reflect attitudes or willingness. Therefore, this item is still included to examine older adults' attitudes. Additionally, fitness equipment is included under exercise stimulation as facilitators of physical activities for older adults (59-62).

Social support mainly refers to meeting with people and friends in the neighborhood, such as gathering with friends in relatively large outdoor spaces in the estates, or watching children play, which add liveliness in older adults' lives $(10,57)$. It is critical for older adults to keep connections with others in society (57). Among various connections, intergenerational programs have become popular among caregiving organizations for older adults (63). Although positive intergenerational relationships are mainly observed in elderly caring facilities, it is suspected to be valid in neighborhoods with mixed generations as well.

For each of the 22 landscape elements and features, participants need to assign a mark on a scale from 0 to 10 , where a higher mark represents higher perceived importance. To assist in analyzing the possible reasons for perceived importance, the time and days that older people would use neighborhood outdoor spaces and their outdoor activities within their estates were also investigated in the questionnaire. Activities were first extracted from the author's previous studies on older adults in Hong Kong $(36,37)$ and were supplemented by pilot studies in the selected PRH estates. These activities were shown in a multiple-choice question in the questionnaire. Participants could tick or supplement to indicate all of their activities in neighborhood outdoor spaces. In addition, demographic information such as age, gender, self-evaluated health, physical

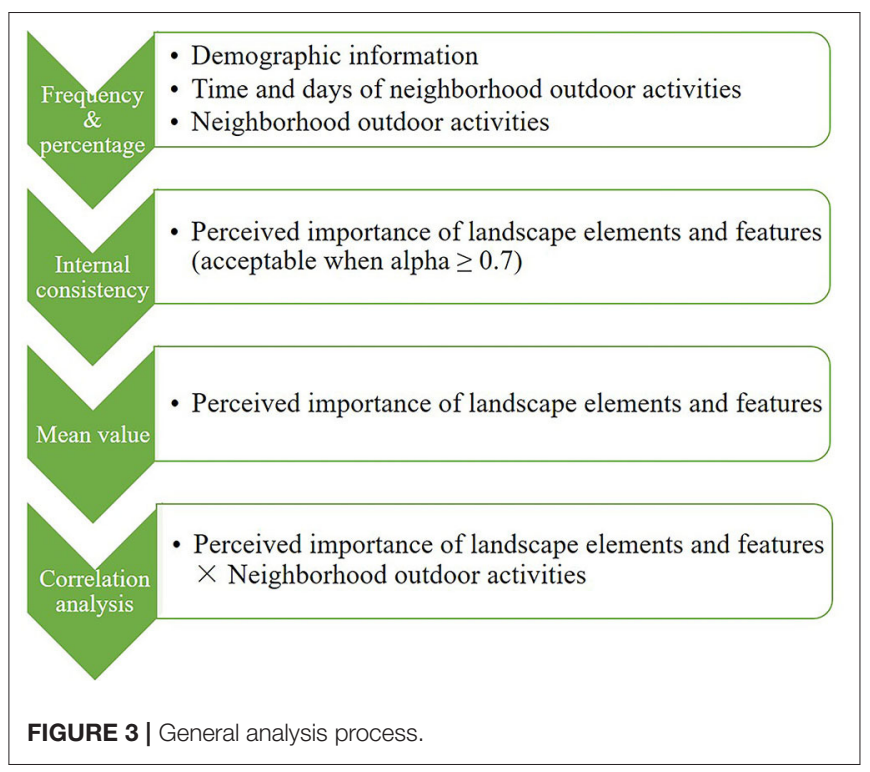

impairment, household composition, and period living in the estate was also collected.

\section{Data Collection and Processing}

The survey was conducted during June and July 2019 in the selected 17 PRH estates. During the survey, people seemingly aged 65 or above were approached randomly and were filtered out if they were not residents in the current estate or aged under 65. During the survey, participants were encouraged to share reasons for their answers and insights into their neighborhood outdoor spaces. Participants were allowed to quit during the survey as they liked. The planned sample size in each estate follows the proportion of the older-resident population in that estate to the sum of those in all 17 estates, based on a total targeted sample size of 420 [considering potential loss in sorting, the targeted sample size was set as 1.1 times the original 381 , which was calculated with 5\% confidence interval, 95\% confidence level, and a target population of 42,851 (64), and rounded up to nearest 10]. Collected data were processed with IBM SPSS 22. The general analysis process is shown in Figure 3 and will be elaborated on below.

\section{RESULTS}

A total of 426 valid samples were collected. Among these, 241 were female (56.6\%) and 185 were male (43.4\%). This is generally consistent with the overall demographic situation among older adults in Hong Kong by mid-2018 (65). Of the participants, $41.5 \%$ claimed that they did not have any chronic diseases; $12.9 \%$ thought their health condition was very good, $46.9 \%$ good, $33.1 \%$ generally ok, and $7 \%$ poor or very poor. The most mentioned chronic diseases were cardiovascular and cerebrovascular $(39.9 \%)$, followed by orthopedics diseases (36.1\%) and diabetes (9.6\%). In terms of physical impairment, 


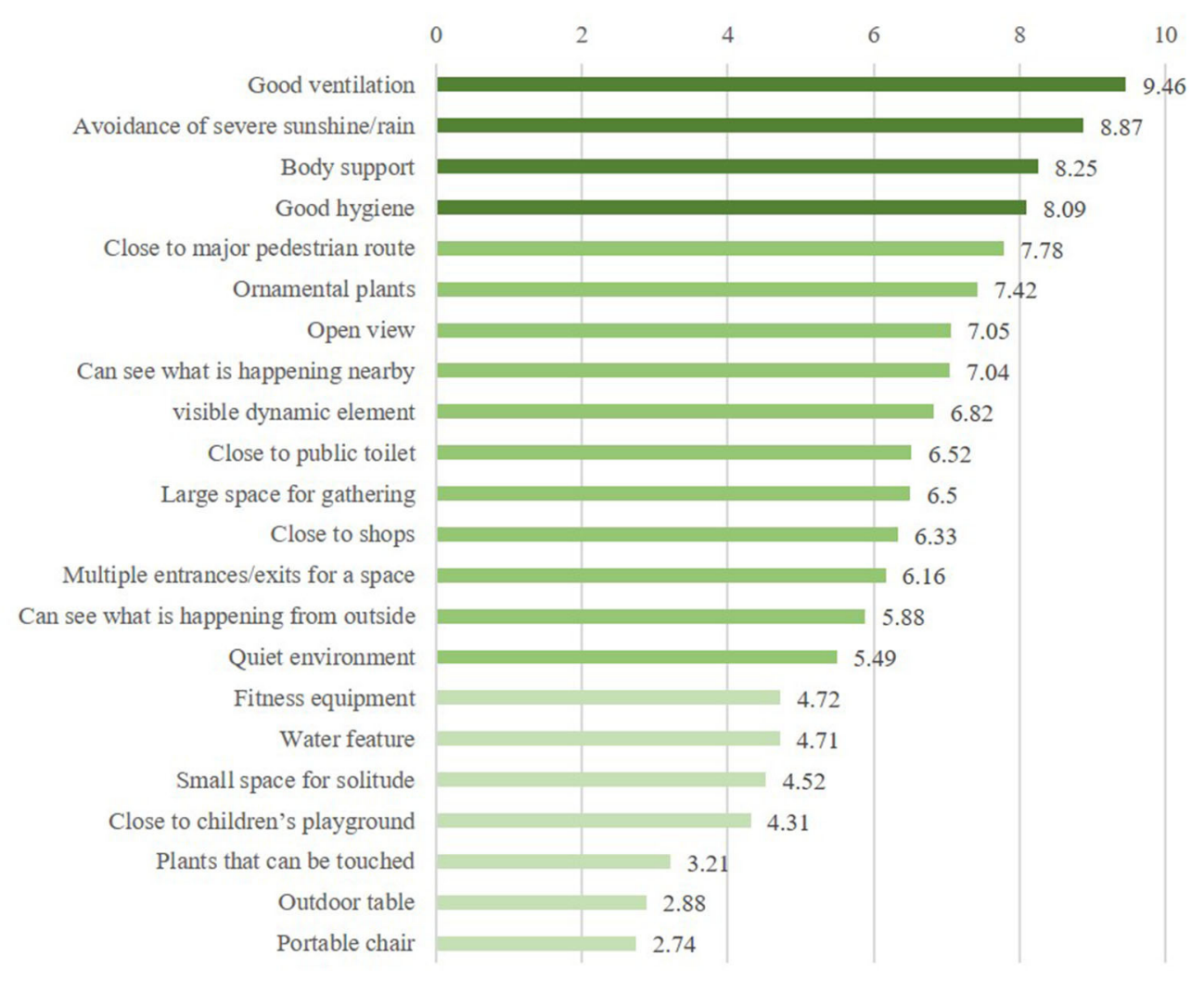

FIGURE 4 | Perceived importance of each landscape element/feature (ranked).

$58.2 \%$ of participants claimed that they did not suffer from any such impairment. Among various impairments, impaired mobility was most common (31\%). Regarding household composition, $34.5 \%$ of participants lived alone, while the rest lived with other people like children, spouses, parents, and domestic helpers.

By the time of this survey, $99.3 \%$ of participants had lived in their estates for more than 1 year and $84 \%$ for more than 10 years. Most participants used open spaces in their estates frequently: $63.6 \%$ used such spaces more than once every day, $27.9 \%$ once every day, and $8.4 \%$ once to twice a week or less. They visited these outdoor spaces on any day throughout a week, except a bit less on public holidays (88.5\%). Considering a single day, around $70 \%$ participants visited the outdoor spaces during 9 a.m. -12 noon and 3-5 p.m., around $40 \%$ came out in early mornings before 9 a.m., $\sim 20 \%$ stayed outside during noon hours, while $<20 \%$ stayed outside after 6 p.m. These responses indicate that most participants visited outdoor spaces in their estates frequently and were familiar with these spaces and the facilities within them and thus that their replies to our survey could be considered reliable.

The internal consistency of the 22 landscape elements and features was examined with a reliability analysis in SPSS. The result for Cronbach's alpha is 0.713 , which indicates an acceptable internal consistency among the 22 items. The perceived importance of the 22 landscape elements and features is represented by the mean values of the item scores received (Figure 4). Generally speaking, landscape elements and features that related to Comfort, i.e., good ventilation, avoidance of severe sunshine/rain, and good hygiene, together with body support under Convenience fall into the high range $(>8.0)$, except that in Comfort, a few items under each of the rest categories fall into the medium (5.0-8.0) and low $(<5.0)$ ranges in terms of perceived importance among participants. Additionally, the frequency and percentage of each type of activity are summarized in Table 3. Those taken part in by $50 \%$ or more of the participants are mainly passive activities.

\section{DISCUSSION AND DESIGN IMPLICATIONS Landscape Elements and Features With High Perceived Importance}

Based on literature review, landscape elements and features that related to Convenience were expected to receive higher rankings in perceived importance. Surprisingly, only Body support under this category was scored as having high perceived importance, while all three items under Comfort were scored highly. To explore the possible reasons for this, correlations between items with perceived importance $>8.0$ and activities conducted by participants were examined. According to Table 4, activities that significantly correlated with items under Comfort were 


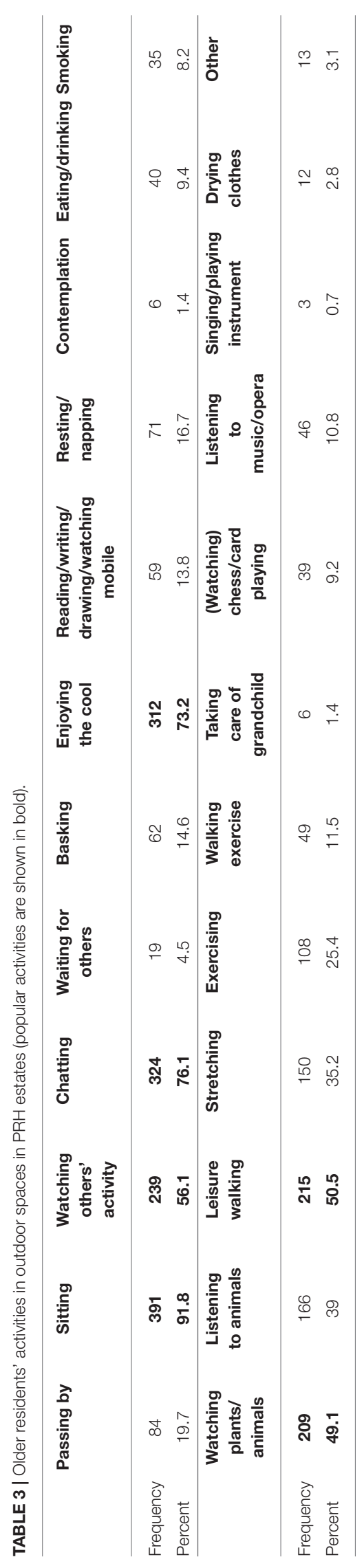

relatively more popular among participants in PRH outdoor spaces (see Table 3). This indicates a high representativeness of these correlations among older adults in their residential outdoor spaces in general.

Good ventilation was negatively correlated with Pass by, which implies that if participants find that the ventilation of a space is good, they tend to stay in it. Furthermore, good ventilation promotes various relaxing and passive activities, like enjoying the cool, watching plants/animals, watching others' activity, and listening to animals. Under such circumstances, people may have an experience similar to meditation and be more sensitive to direct sensations (66). During hot days, good ventilation with breezes can effectively strengthen evaporation on the skin, hence improving thermal comfort (67). This could encourage leisure walking and stretching as well as outdoor activities in general among older adults.

Avoidance of severe sunshine/rain in outdoor spaces seems to be more influential on activities with a potentially long duration, like sitting, watching others' activity, chatting, enjoying the cool, watching plants/animals, listening to animals, and leisure walking. It appears critical to activities that rely heavily on vision, such as eating/drinking and playing chess/cards, as older adults can be easily affected by strong light or glare due to deteriorated vision and visual impairment (68). Besides lighting conditions, rain can also affect older adults' use of outdoor spaces. Most of the participants told us that they would stay indoor if it was raining. However, if a shower came when they were already outside, they would be easily caught by the rain, as many of them move slowly and are afraid of falling due to rushing or the wet ground. Therefore, if there are shelters that can protect them from the showers, older adults can enjoy their outdoor activities without worrying about sudden changes in the weather.

High perceived importance of Good hygiene is probably rooted in participants' consciousness that a space with poor hygiene could harm their health. Since maintaining health is critical and even challenging to most older adults, it is understandable that they would not put themselves at such risk. Regarding associations with activities, Good hygiene is positively correlated with rest, watching plants/animals, listening to animals, leisure walking, and exercise. Actually, some participants expressed reservations about birds or other animals, for these animals may spread bird flu or other diseases, and their feces can stain the environment. This could partially explain why older adults emphasize the hygiene of an outdoor space while they enjoy small animals around them.

Another highly scored element is Body support under the category of Convenience. This item covers various seating facilities and alternatives such as planter edges that are suitable for sitting and elements (railings) at waist or back height to support leaning. It is more associated with static activities, especially long-lasting ones, e.g., watching others' activity, enjoying the cool, watching plants/animals, and listening to animals (Table 4). In order to help sustain older adults' selfesteem, it is better to integrate these body support elements into general landscape design instead of making them specifically for older adults. 


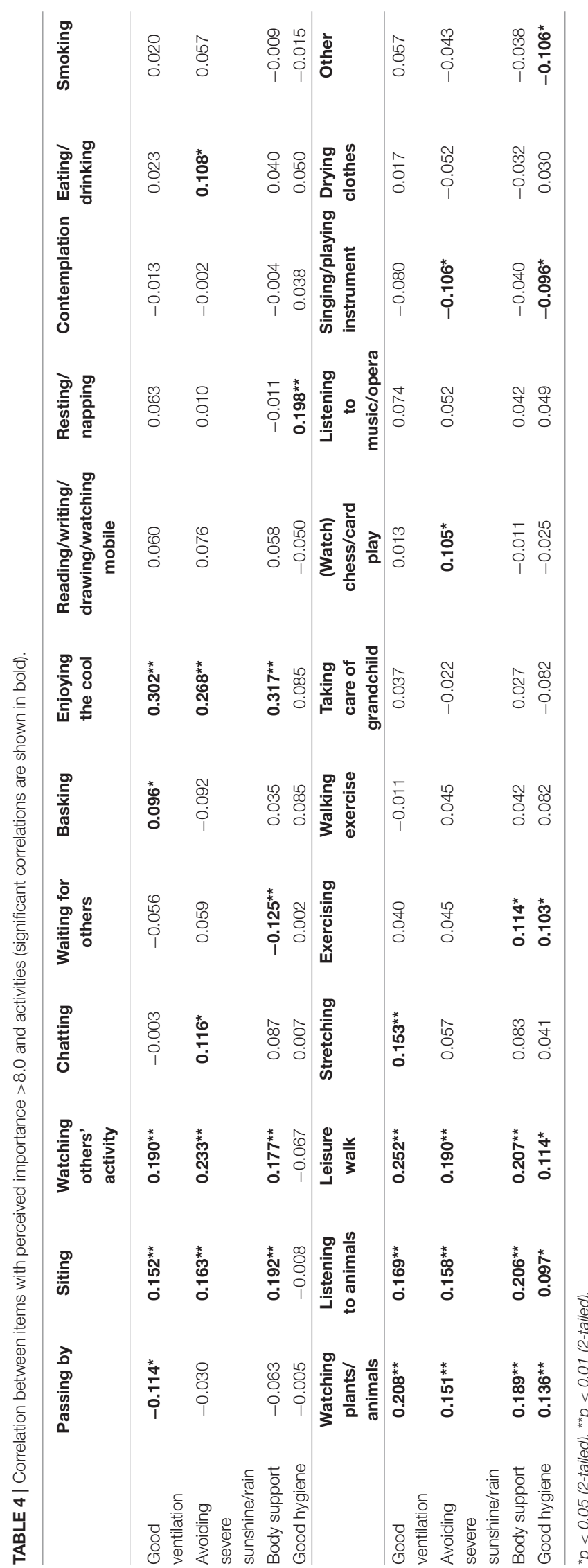

\section{Landscape Elements and Features With Low Perceived Importance}

Landscape elements and features with an average mark of $<5.0$ include Fitness equipment, Water feature, and Plants that can be touched under the category of Stimulation, Small spaces for solitude and Portable chairs under Sense of control, Close to children's playground under Social support, and Outdoor tables under Convenience. These outcomes are surprising, as all of these items have been stressed in various design guidelines for older adults $(12,30,53,69)$. Again, associations between these items and activities, together with comments received during the surveys are examined to facilitate interpretation (Table 5).

Regarding Fitness equipment, some participants commented that it was more suitable for healthy and young people with a higher level of strength. Some also mentioned that many types of fitness equipment were over-sized for them. Older adults who often do stretches and exercise may not have such problems and also use fitness equipment more (Table 5). Nonetheless, demands for properly designed fitness equipment should not be denied. A good approach would be to provide aging-friendly fitness equipment to encourage exercise among older adults and further contribute to their well-being through a more physically active lifestyle $(70,71)$.

Water features, Close to children's playground, Plants that can be touched, Outdoor tables, and Portable chairs are considered less important by participants mainly due to safety concerns. For Water features, some participants told us that children would play in the water and wet the ground nearby, which would be slippery. Similarly, children may cause other hazards if they play close to older adults. For instance, children would occasionally bump into people when running around. This could injure older adults seriously. One participant told us that she was once knocked down by a child in her estate and suffered a broken bone. Despite these issues, children's contribution to liveliness is highly appreciated in these estates with high proportions of older adults. For Plants that can be touched, relatively active people, like those who take part in exercise or stretching, may be more sensitive to lively elements and appear to consider it somewhat important (Table 5). In reality, few people take action although many said that they would like to touch beautiful or lovely plants if they came across them, mainly due to the application of pesticides discussed above.

Regarding outdoor tables, participants shared that some people partied around them until midnight, made a lot of noises, and dirtied the place; in some other cases, there were quarrels between different people competing to use the tables. In most cases, outdoor tables were dismantled by property management in the end. For portable chairs, even though many participants reflected that seating is inadequate in their estates, they did not like portable chairs. They commonly worried about falling while sitting down or standing up or tripping over while walking if the chairs were not fixed. Seemingly the only case that outdoor tables and portable chairs are in need is for (watching) playing chess/cards (Table 5). This is supported by frequent observations of older adults who play chess/cards on benches or even on planter edges and attract crowds around them. 
TABLE 5 | Correlation between items with perceived importance $<5.0$ and activities (significant correlations are shown in bold).

\begin{tabular}{|c|c|c|c|c|c|c|c|c|c|c|c|c|}
\hline & Passing by & Sitting & $\begin{array}{l}\text { Watching } \\
\text { others' } \\
\text { activity }\end{array}$ & Chatting & $\begin{array}{l}\text { Waiting for } \\
\text { others }\end{array}$ & Basking & $\begin{array}{l}\text { Enjoying } \\
\text { the cool }\end{array}$ & $\begin{array}{c}\text { Reading/writing/ } \\
\text { drawing/watching } \\
\text { mobile }\end{array}$ & $\begin{array}{l}\text { Resting/ } \\
\text { napping }\end{array}$ & Contemplation & $\begin{array}{l}\text { Eating/ } \\
\text { drinking }\end{array}$ & Smoking \\
\hline Fitness equipment & $0.106^{*}$ & -0.078 & $-0.133^{\star \star}$ & 0.059 & -0.040 & 0.039 & -0.059 & -0.071 & 0.050 & -0.007 & 0.011 & 0.027 \\
\hline Water feature & 0.055 & 0.050 & 0.036 & 0.036 & -0.055 & 0.013 & 0.039 & -0.008 & 0.013 & 0.085 & 0.062 & 0.070 \\
\hline $\begin{array}{l}\text { Small space for } \\
\text { solitude }\end{array}$ & $0.106^{\star}$ & -0.012 & -0.070 & $-0.154^{\star *}$ & 0.089 & 0.083 & $-0.117^{\star}$ & 0.066 & 0.000 & -0.007 & -0.067 & 0.022 \\
\hline $\begin{array}{l}\text { Close to children's } \\
\text { playground }\end{array}$ & 0.024 & -0.083 & 0.033 & 0.078 & -0.094 & 0.054 & 0.040 & -0.027 & 0.025 & 0.024 & $0.143^{\star \star}$ & 0.030 \\
\hline $\begin{array}{l}\text { Plants that can be } \\
\text { touched }\end{array}$ & $0.106^{*}$ & -0.078 & $-0.133^{\star *}$ & 0.059 & -0.040 & 0.039 & -0.059 & -0.071 & 0.050 & -0.007 & 0.011 & 0.027 \\
\hline Outdoor table & 0.080 & -0.077 & -0.043 & -0.013 & $0.153^{\star \star}$ & 0.000 & $-0.114^{\star}$ & 0.038 & 0.032 & -0.033 & -0.081 & 0.035 \\
\hline \multirow[t]{2}{*}{ Portable chair } & 0.065 & -0.018 & $-0.103^{*}$ & 0.008 & -0.029 & 0.070 & -0.066 & -0.021 & -0.060 & -0.070 & -0.012 & 0.095 \\
\hline & $\begin{array}{l}\text { Watching } \\
\text { plants/animal }\end{array}$ & $\begin{array}{l}\text { Listening } \\
\text { to animals }\end{array}$ & $\begin{array}{l}\text { Leisure } \\
\text { walking }\end{array}$ & Stretching & Exerciseing & $\begin{array}{l}\text { Walking } \\
\text { exercise }\end{array}$ & $\begin{array}{l}\text { Taking } \\
\text { care of } \\
\text { grandchild }\end{array}$ & $\begin{array}{l}\text { (Watching) } \\
\text { chess/card } \\
\text { playing }\end{array}$ & $\begin{array}{l}\text { Listening } \\
\text { to } \\
\text { music/opera }\end{array}$ & $\begin{array}{l}\text { Singing/playing } \\
\text { instrument }\end{array}$ & $\begin{array}{l}\text { Drying } \\
\text { clothes }\end{array}$ & Other \\
\hline Fitness equipment & -0.049 & -0.017 & -0.127 & $0.153^{\star \star}$ & $0.281^{\star *}$ & 0.021 & -0.022 & 0.049 & 0.045 & -0.016 & 0.016 & 0.006 \\
\hline Water feature & $0.109^{*}$ & $0.138^{\star \star}$ & 0.035 & 0.071 & $0.170^{* *}$ & -0.058 & -0.036 & $0.100^{*}$ & 0.009 & 0.032 & 0.068 & -0.049 \\
\hline $\begin{array}{l}\text { Small space for } \\
\text { stay alone }\end{array}$ & -0.055 & -0.057 & $-0.147^{\star \star}$ & -0.094 & $-0.097^{\star}$ & 0.054 & -0.048 & -0.088 & 0.000 & 0.012 & -0.077 & -0.060 \\
\hline $\begin{array}{l}\text { Close to children's } \\
\text { playground }\end{array}$ & $0.121^{*}$ & $0.153^{\star \star}$ & 0.053 & 0.072 & 0.078 & -0.036 & $0.106^{*}$ & 0.011 & 0.037 & -0.008 & 0.030 & 0.064 \\
\hline $\begin{array}{l}\text { Plants that can be } \\
\text { touched }\end{array}$ & -0.049 & -0.017 & $-0.127^{\star \star}$ & $0.153^{\star \star}$ & $0.281^{* *}$ & 0.021 & -0.022 & 0.049 & 0.045 & -0.016 & 0.016 & 0.006 \\
\hline Outdoor table & -0.064 & -0.039 & -0.062 & 0.002 & 0.011 & 0.006 & -0.027 & $0.181^{\star *}$ & -0.039 & 0.090 & 0.046 & 0.028 \\
\hline Portable chair & $-0.117^{\star}$ & $-0.130^{\star \star}$ & $-0.185^{\star \star}$ & 0.001 & 0.034 & -0.035 & -0.009 & $0.173^{\star \star}$ & 0.020 & 0.015 & -0.061 & -0.079 \\
\hline
\end{tabular}

${ }^{*} p<0.05$ (2-tailed), ${ }^{* *} p<0.01$ (2-tailed). 
Considering Small spaces for solitude, four out of five significant correlations between this item and activities are negative (Table 5). This indicates that older adults tend to be aggregation-oriented, even with little interaction. One reason for this would be that many of them live alone $(34.5 \%$ of the participants in this study). Such an isolated or semi-isolated life could be stressful for many people, especially vulnerable older adults $(72,73)$. It may also lead to loneliness and depression and affect their quality of life (74). From this perspective, older adults need a sense of been connected with society, which could be largely achieved by spending time with others in neighborhood outdoor spaces. Another possible reason could be that older adults would not feel released in an outdoor space that is similar to or even smaller than their residence in size. Therefore, this study reveals that compared to small spaces with high privacy, older adults prefer spacious ones that can support a certain extent of gathering.

\section{Landscape Elements and Features With Medium Perceived Importance}

The remaining landscape elements and features had medium perceived importance, including Close to major pedestrian route, Close to public toilet, and Close to shops under the Convenience category; Ornamental plants, Open view, and Visible dynamic element under Stimulation; Can see what is happening nearby, Can see what is happening from outside, and Quiet environment under Sense of safety; Large space for gathering under Social support; and Multiple entrances/exits for a space under Sense of control.

Seemingly, items under Convenience and Stimulation are relatively important within this range. They mainly represent supportive distance and the interestingness of views. If considered integrally with Body support, this implies that if sufficient body support elements or facilities were provided, older adults would not mind walking farther. This could be a valuable reference for neighborhood outdoor space design and even for community planning with special concerns about older adults. Views inwards to and outwards from a space could be easily realized simultaneously when creating open views and could be better integrated with locomotional access, i.e., entrances to spaces. Regarding sharing a space with others, older adults in this study showed less concern. This can be explained by their low intention to spend time alone in outdoor spaces as discussed above. However, they seem not to be proactive for Social support either, as many thought themselves too old and weak to engage in organized activities. The only significantly correlated activities with this item are chatting $(r=0.333, p$ $=0.000)$, rest/nap $(r=0.125, p=0.010)$, and exercise $(r$ $=0.122, p=0.012)$. Chatting and exercising are commonly observed to be conducted by different people together, often with interactions. Resting/napping in a crowd or next to other people may contribute to a sense of safety or being connected to the society. It seems that older adults in the studied estates tend to make minimal effort to maintain social connections and avoid loneliness, which has been commonly agreed as a predictor of functional decline $(6,7)$.

\section{Design Implications}

Our findings regarding the perceived importance of neighborhood landscape elements and features for older adults generate some landscape design suggestions. These could supplement existing guidelines and recommendations concerning aging-friendly landscape design:

- Weather-related solutions such as good ventilation and weather protection should be provided carefully so as to improve the general outdoor experience for older adults. This would be especially important for places with hot seasons and high annual rainfalls.

- Water features and children's playground can add a lot of interest and liveliness to neighborhoods, which could greatly enrich older adults' outdoor experience. However, they may also become hazards to older adults. Therefore, it is better to locate them at a certain distance from major routes and spaces that are heavily used by older adults while providing visual and acoustic connections in between. Level differences, short fences, or hedges between these spaces may help to achieve such safe connections.

- The safety issues of any portable facilities or elements, like portable chairs, should be carefully considered. In order to ensure the safety of older adults while fulfilling the needs of other age groups in neighborhoods, it is suggested to locate such facilities away from major routes and spaces that are used heavily by older adults.

- The boundaries of each single space should be designed to ensure good in-outward visual connections to support timely help when needed and to avoid any corner or spot that may lead to hygiene problems. These approaches can also contribute to security in outdoor spaces, especially those that lack CCTV coverage. It would be good to integrate space boundaries with natural elements so as to enrich interest and strengthen the well-being benefits of outdoor spaces.

- The sizes of facilities should be carefully decided or adjusted for older adults rather than simply applying standard ones. This is especially important for fitness equipment and benches, which could bring a lot of benefits and are in great need.

\section{LIMITATIONS}

Neighborhood outdoor spaces are complex systems that involve numerous interactive factors. Although the landscape elements and features investigated in this study are extracted from a comprehensive literature review and are supplemented by initial site observations, there may still be important ones for aging in place yet to be covered. Besides, this study focuses on $\mathrm{PRH}$ estates, which leads to a relatively limited diversity in older residents, landscape designs, and property management. If older adults from other socio-economic groups and different types of residential developments such as private ones could be included, the findings would be enriched and more comprehensive for neighborhood landscapes. Furthermore, this study emphasizes the subjective perceptions of participants. The cross-sectional data employed in this study illustrate such perceptions at a certain point in time. However, perceived importance may evolve with 
the development of the entire society. To further understand the evolution of perceived importance over time, longitudinal data would be necessary. Moreover, the rigor of the study could be strengthened if supported with objective measurements and analyses on the landscape elements and features. When research on this topic goes deeper, different characteristics of older adults could be further discussed to generate more specific and detailed design recommendations. These would be potential directions for future research in this field.

\section{CONCLUSION}

This study investigated the perceived relative importance of 22 neighborhood landscape elements and features from the perspective of older adults. It reveals that older adults tend to judge the importance of any landscape element or feature upon comprehensive evaluation of the potential benefits and hazards it would bring, especially emphasizing comfort and safety.

Landscape elements or features that contribute to comfort and help avoid hazards, like good ventilation, avoidance of severe sunshine/rain, body support, and good hygiene, are considered highly important by older adults. Sufficient provision and proper design of these are critical for older adults so that they can use outdoor spaces or avoid difficulties in moving around in their neighborhoods or avoid being attacked by germs, which may threaten their well-being and quality of life. Therefore, these are found to be fundamental landscape elements and features for older adults and should be given priority in neighborhood landscape design.

In contrast, any landscape element or feature that may bring hazards while not being a necessity for older adults' outdoor experience is considered least important. This group comprises portable chairs, outdoor tables, plants that can be touched, closeness to a children's playground, small spaces for solitude, water features, and fitness equipment. If safety concerns could be addressed properly, these landscape elements and features would still be appreciated by older adults.

In between the above two clusters are landscape elements and features that are perceived as of medium importance by older adults. They commonly have alternatives and are not considered necessities. Being close to major routes, ornamental plants, open views, visual contacts inward toward and outward from a space, visible dynamic elements, availability of public toilets, a large

\section{REFERENCES}

1. Department of Economic Social Affairs UN. World Population Prospects 2019 (Highlights). New York, NY (2019).

2. Persons AAOR. 2018 Home and Community Preferences Survey Chartbook. (2018). Available online at: https://www.aarp.org/content/dam/aarp/research/ surveys_statistics/liv-com/2018/home-community-preferences-chartbook. doi.10.26419-2Fres.00231.002.pdf

3. Rosenwohl-Mack A, Schumacher K, Fang M-L, Fukuoka Y. A new conceptual model of experiences of aging in place in the United States: results of a systematic review and meta-ethnography of qualitative studies. Int J Nurs Stud. (2020) 103:103496. doi: 10.1016/j.ijnurstu.2019. 103496 space for gathering, being close to shops, multiple entrances to a space, and a quiet environment all fall within this group. These elements and features are not that fundamental but would affect the richness and convenience of the outdoor experience of older adults to a certain extent, especially through contact with nature.

Based on our findings of the perceived relative importance of these neighborhood landscape elements and features, some landscape design suggestions were generated to supplement existing guidelines and recommendations concerning older adults' well-being and quality of life. These will be valuable for neighborhood landscape research and for designs that prioritize promoting aging in place effectively.

\section{DATA AVAILABILITY STATEMENT}

All datasets generated for this study are included in the article/supplementary files.

\section{ETHICS STATEMENT}

The studies involving human participants were reviewed and approved by the Human Subjects Ethics Sub-committee (HSESC) of THEi, Hong Kong S.A.R. Written informed consent for participation was not required for this study in accordance with the national legislation and the institutional requirements.

\section{AUTHOR CONTRIBUTIONS}

The author designed the study, participated and monitored data collection, conducted data analyses, data interpretation, and prepared this article.

\section{FUNDING}

This study was funded by the Hong Kong S.A.R. Research Grants Council (RGC) (Ref. No. UGC/FDS25/H05/18).

\section{ACKNOWLEDGMENTS}

The author was thankful to all participants for supporting this study. Thanks are also given to all student helpers for assisting in data collection. 
8. Rantz MJ, Phillips L, Aud M, Popejoy L, Marek KD, Hicks LL. Evaluation of aging in place model with home care services and registered nurse care coordination in senior housing. Nurs Outlook. (2011) 59:37-46. doi: 10.1016/j.outlook.2010.08.004

9. Sugiyama T, Thompson CW. Older people's health, outdoor activity and support-iveness of neighbourhood environments. Landsc Urban Plann. (2007) 83:168-75. doi: 10.1016/j.landurbplan.2007.04.002

10. Sugiyama T, Thompson CW, Alves S. Associations between neighborhood open space attributes and quality of life for older people in Britain. Environ Behav. (2009) 41:3-21. doi: 10.1177/0013916507311688

11. Beyer KM, Kaltenbach A, Szabo A, Bogar S, Nieto FJ, Malecki KM. Exposure to neighborhood green space and mental health: evidence from the survey of the health of Wisconsin. Int J Environ Res Public Health. (2014) 11:3453-72. doi: $10.3390 /$ ijerph110303453

12. Cooper Marcus C, Barnes M. Healing Gardens: Therapeutic Benefits and Design Recommendations. Hoboken, NJ: John Wiley \& Sons (1999).

13. Hartig T, Evans GW. Psychological foundations of nature experience. In: Garling T, Golledge RG, editors. Behavior and Environment: Psychological and Geographical Approaches. North-Holland: Elsevier (1993). p. 427-57.

14. Ulrich RS. Effects of gardens on health outcomes: theory and research. In: Marcus CC, Barnes M, editors. Healing Gardens: Therapeutic Benefits and Design Recommendations. New York, NY: John Wiley \& Sons (1999). p. 27-86.

15. Sugiyama T, Thompson CW. Outdoor environments, activity and the wellbeing of older people: conceptualising environmental support. Environ Plann. (2007) 39:1943-60. doi: 10.1068/a38226

16. Kaplan S. The restorative benefits of nature: toward an integrative framework. J Environ Psychol. (1995) 15:169-82. doi: 10.1016/0272-4944(95)90001-2

17. Cox H, Burns I, Savage S. Multisensory environments for leisure: promoting well-being in nursing home residents with dementia. J Gerontol Nurs. (2004) 30:37-45. doi: 10.3928/0098-9134-20040201-08

18. Murphy PF, Miyazaki Y, Detweiler MB, Kim KY. Longitudinal analysis of differential effects on agitation of a therapeutic wander garden for dementia patients based on ambulation ability. Dementia. (2010) 9:355-73. doi: $10.1177 / 1471301210375336$

19. McAuley E, Konopack JF, Motl RW, Morris KS, Doerksen SE, Rosengren KR. Physical activity and quality of life in older adults: influence of health status and self-efficacy. Ann Behav Med. (2006) 31:99-103. doi: 10.1207/s15324796abm3101_14

20. Takano T, Nakamura K, Watanabe M. Urban residential environments and senior citizens' longevity in megacity areas: the importance of walkable green spaces. J Epidemiol Commun Health. (2002) 56:913-8. doi: $10.1136 /$ jech.56.12.913

21. Wiles JL, Allen RES, Palmer AJ, Hayman KJ, Keeling S, Kerse N. Older people and their social spaces: a study of well-being and attachment to place in Aotearoa New Zealand. Soc Sci Med. (2009) 68:664-71. doi: 10.1016/j.socscimed.2008.11.030

22. Brown DK, Barton JL, Gladwell VF. Viewing nature scenes positively affects recovery of autonomic function following acute-mental stress. Environ Sci Technol. (2013) 47:5562-9. doi: 10.1021/es305019p

23. Ulrich RS. Visual landscapes and psychological well-being. Landsc Res. (1979) 4:17-23. doi: 10.1080/01426397908705892

24. Ulrich RS. View through a window may influence recovery from surgery. Science. (1984) 224:420-1. doi: 10.1126/science.6143402

25. Kamin ST, Beyer A, Lang FR. Outdoor motivation moderates the effects of accessibility on mobility in old age. Z Gerontol Geriat. (2016) 49:372-8. doi: 10.1007/s00391-015-0946-4

26. Loo BPY, Lam WWY, Mahendran R, Katagiri K. How is the neighborhood environment related to the health of seniors living in Hong Kong, Singapore, and Tokyo? Some insights for promoting aging in place. Ann Am Assoc Geograph. (2017) 107:812-28. doi: 10.1080/24694452.2016.1271306

27. Tan Z, Lau KK, Roberts AC, Chao ST, Ng E. Designing urban green spaces for older adults in Asian cities. Int J Environ Res Public Health. (2019) 16:E4423. doi: $10.3390 /$ ijerph 16224423

28. Yen IH, Fandel Flood J, Thompson H, Anderson LA, Wong G. How design of places promotes or inhibits mobility of older adults: realist synthesis of 20 years of research. J Aging Health. (2014) 26:1340-72. doi: $10.1177 / 0898264314527610$
29. Zandieh R, Martinez J, Flacke J, Jones P, van Maarseveen. M. Older adults' outdoor walking: inequalities in neighbourhood safety, pedestrian infrastructure and aesthetics. Int J Environ Res Public Health. (2016) 13:1179. doi: 10.3390/ijerph13121179

30. Cooper Marcus C, Sachs NA. Therapeutic Landscapes: An Evidence-Based Design Approach to Designing of Healing Gardens and Restorative Outdoor Spaces. Hoboken, NJ: John Wiley and Sons (2014).

31. Lawton MP. Environment and aging: theory revisited. In: Scheidt RJ, Windley PG, editors. Environment and Aging Theory. A Focus on Housing. Westport: Greenwood Press (1998). p. 1-31.

32. Kweon B-S, Sullivan WC, Wiley AR. Green common spaces and the social integration of inner-city older adults. Environ Behav. (1998) 30:832-58. doi: $10.1177 / 001391659803000605$

33. Levasseur M, Généreux M, Bruneau JF, Vanasse A, Chabot É, Beaulac C, et al. Importance of proximity to resources, social support, transportation and neighborhood security for mobility and social participation in older adults: results from a scoping study. BMC Public Health. (2015) 15:503. doi: 10.1186/s12889-015-1824-0

34. Queensland Government. Design Guidelines for Queensland Residential Aged Care Facilities (1999). Available online at: https://www.health.qld.gov.au/_ data/assets/pdf_file/0025/151099/qh-gdl-374-8.pdf

35. Regnier V. Designing for Assisted Living: Guidelines for Housing the Physically and Mentally Frail. New York, NY: John Wiley \& Sons (2002).

36. Shi S, Tong C, Cooper Marcus. C. What makes a garden in elderly care facility well used? Landsc Res. (2019) 44:256-69. doi: 10.1080/01426397.2018.14 57143

37. Shi S, Tong C, Tao Y. How does spatial organization of gardens at care facilities for the elderly influence use patterns: a case study in Hong Kong. Landsc Res. (2018) 43:124-38. doi: 10.1080/01426397.2017.1305345

38. Census Statistics Department, HKSAR. Hong Kong in Figures. Hong Kong: Census and Statistics Department (2019).

39. Census Statistics Department, HKSAR. Hong Kong Population Projections for 2017-2066 Released. (2017). Available online at: https://www.censtatd.gov.hk/ press_release/pressReleaseDetail.jsp?charsetID $=18$ pressRID $=4200$

40. Census Statistics Department, HKSAR. Thematic Household Survey Report No. 40. Socio-Demographic Profile, Health Status and Self-Care Capability of Older Persons. Hong Kong (2009). Available online at: http://www. censtatd.gov.hk/freedownload.jsp?file=publication/stat_report/social_data/ B11302402009XXXXB0100.pdf\&title=\%a5D\%c3D\%a9\%ca\%a6\%ed\%a4\%e1 \%b2\%ce\%adp\%bd\%d5\%acd\%b3\%f8\%a7i\%ae\%d1\$ $\mid$ pm\$-\$pm\$\%b2\%c4\%a5 \%7c\%a4Q\%b8\%b9\%b3\%f8\%a7i\%ae\%d1 \&issue $=-$ \&lang $=2 \& \mathrm{c}=1$

41. Jayantha WM, Qian QK, Yi CO. Applicability of 'Aging in Place' in redeveloped public rental housing estates in Hong Kong. Cities. (2018) 83:140-51. doi: 10.1016/j.cities.2018.06.016

42. Census and Statistics Department, HKSAR. Population in Domestic Households by Household Size, Age, Year, Sex and Household Composition (2017). Available online at: http://www.bycensus2016.gov. $\mathrm{hk} / \mathrm{en} / \mathrm{bc}-\mathrm{mt} . \mathrm{html}$

43. Zhang H, Jim CY. Contributions of landscape trees in public housing estates to urban biodiversity in Hong Kong. Urban Forest Urban Green. (2014) 13:272-84. doi: 10.1016/j.ufug.2013.12.009

44. Census Statistics Department, HKSAR. District Profiles: Major Housing Estates. The Government of HKSAR (2017). Available online at: http://www. bycensus2016.gov.hk/en/bc-dp-major-hosing-estates.html

45. Campbell N. Designing for social needs to support aging in place within continuing care retirement communities. J Housing Built Environ. (2015) 30:645-65. doi: 10.1007/s10901-015-9437-6

46. Frank L, Kerr J, Rosenberg D, King A. Healthy aging and where you live: Community design relationships with physical activity and body weight in older Americans. J Phys Activity Health. (2010) 7:82-90. doi: 10.1123/jpah.7.s1.s82

47. Satariano W, Ivey S, Kurtovich E, Kealey M, Hubbard A, Bayles C. Lowerbody function, neighborhoods, and walking in an older population. Am J Prev Med. (2010) 38:419-28. doi: 10.1016/j.amepre.2009.12.031

48. Glass TA, Balfour JL. Neighborhoods, aging, functional limitations. In: Kawachi I, Berkman LF, editors. Neighborhoods and Health. New York, NY: Oxford University Press (2003). p. 303-34. 
49. Stathi A, Gilbert H, Fox KR, Coulson J, Davis M, Thompson JL. Determinants of neighborhood activity of adults age 70 and over: a mixedmethods study. J Aging Phys Activity. (2012) 20:148-70. doi: 10.1123/japa. 20.2.148

50. Nagel CL, Carlson NE, Bosworth M, Michael YL. The relation between neighborhood built environment and walking activity among older adults. Am J Epidemiol. (2008) 168:461-8. doi: 10.1093/aje/kwn158

51. Strach S, Isaacs R, Greenwald M. Operationalizing environmental indicators for physical activity in older adults. J Aging Phys Activity. (2007) 15:412-24. doi: 10.1123/japa.15.4.412

52. Rodiek S. Resident perceptions of physical environment features that influence outdoor usage at assisted living facilities. In: Rodiek S, Schwarz Binghamton B, editors. The Role of the Outdoors in Residential Environmetns for Aging. New York, NY: Haworth Press (2005). p. 95-108.

53. Tyson MM. The Healing Landscape: Therapeutic Outdoor Environments. New York, NY: McGraw-Hill (1998).

54. Kaplan R, Austin ME. Out in the country: sprawl and the quest for nature nearby. Landsc Urban Plann. (2004) 69:235-43. doi: 10.1016/j.landurbplan.2003.09.006

55. Han A-R, Park S-A, Ahn B-E. Reduced stress and improved physical functional ability in elderly with mental health problems following a horticultural therapy program. Complement Ther Med. (2018) 38:19-23. doi: 10.1016/j.ctim.2018.03.011

56. Santos DA, Silva AM, Baptista F, Santos R, Vale S, Mota J, et al. Sedentary behavior and physical activity are independently related to functional fitness in older adults. Exp Gerontol. (2012) 47:908-12. doi: 10.1016/j.exger.2012.07.011

57. Bowling A, Gabriel Z, Dykes J, Dowding LM, Evans O, Fleissig A, et al. Let's ask them: a national survey of definitions of quality of life and its enhancement among people aged 65 and over. Int J Aging Hum Dev. (2003) 56:269-306. doi: 10.2190/BF8G-5J8L-YTRF-6404

58. Lachman ME, Neupert SD, Agrigoroaei S. The relevance of control beliefs for health and aging. In: Schaie KW, Willis SL, editors. Handbooks of Aging, Handbook of the Psychology of Aging. 7th ed. London: Academic Press (2011). p. 175-90.

59. Ku PW, Steptoe A, Liao Y, Sun WJ, Chen LJ. Prospective relationship between objectively measured light physical activity and depressive symptoms in later life. Int J Geriatric Psychiatry. (2018) 33:58-65. doi: 10.1002/gps.4672

60. Lazarus NR, Harridge SDR. The inherent human aging process and the facilitating role of exercise. Front Physiol. (2018) 9:1135. doi: 10.3389/fphys.2018.01135

61. Rejeski WJ, Mihalko SL. Physical activity and quality of life in older adults. J Gerontol A Biol Sci Med Sci. (2001) 56:23-35. doi: 10.1093/gerona/56.suppl_2.23

62. Zhang CJP, Barnett A, Sit CHP, Lai P-c, Johnston JM, Lee RSY, et al. To what extent does physical activity explain the associations between neighborhood environment and depressive symptoms in older adults living in an Asian metropolis? Mental Health Phys Activity. (2019) 16:96-104. doi: 10.1016/j.mhpa.2018.11.005
63. Mitchell J. All Ages Making a Difference: the Benefits of Intergenerational Partnerships. (2016). Available online at: https://www.leadingage.org/ magazine/septemberoctober-2016/all-ages-making-difference-benefitsintergenerational-partnerships

64. Creative Research Systems. Sample Size Calculator. (2012). Available online at: https://www.surveysystem.com/sscalc.htm\#one

65. Census Statistics Department, HKSAR. Demographic Characteristics. (2019). Available online at: https://www.censtatd.gov.hk/hkstat/sub/gender/ demographic/index.jsp

66. Amarasekera AT, Chang D. Buddhist meditation for vascular function: a narrative review. Integr Med Res. (2019) 8:252-6. doi: 10.1016/j.imr.2019.11.002

67. Bravo G, González E. Thermal comfort in naturally ventilated spaces and under indirect evaporative passive cooling conditions in hot-humid climate. Energy Build. (2013) 63:79-86. doi: 10.1016/j.enbuild.2013. 03.007

68. Owsley C. Aging and vision. Vision Res. (2011) 51:1610-22. doi: 10.1016/j.visres.2010.10.020

69. Winterbottom D, Wagenfeld A. Therapeutic Gardens: Design for Healing Gardens. London: Timber Press (2015).

70. Hamer M, Chida Y. Physical activity and risk of neurodegenerative disease: a systematic review of prospective evidence. Psychol Med. (2009) 39:3-11. doi: $10.1017 /$ S0033291708003681

71. Nelson ME, Rejeski WJ, Blair SN, Duncan PW, Judge JO, King AC, et al. Physical activity and public health in older adults: recommendation from the American College of Sports Medicine and the American Heart Association. Med Sci Sports Exerc. (2007) 39:1435-45. doi: 10.1249/mss.0b013e318 $0616 a a 2$

72. Beekman AT, Deeg DJ, van Tilburg T, Smit JH, Hooijer C, van Tilburg W. Major and minor depression in later life: a study of prevalence and risk factors. J Affect Disord. (1995) 36:65-75. doi: 10.1016/0165-0327(95)00061-5

73. Cacioppo JT, Hughes ME, Waite LJ, Hawkley LC, Thisted RA. Loneliness as a specific risk factor for depressive symptoms: cross-sectional and longitudinal analyses. Psychol Aging. (2006) 21:140-51. doi: 10.1037/0882-7974.21.1.140

74. Rico-Uribe LA, FélixCaballero F, Olaya B, Tobiasz-Adamczyk B, Koskinen $\mathrm{S}$, Leonardi $\mathrm{M}$, et al. Loneliness, social networks, and health: a crosssectional study in three countries. PLoS ONE. (2016) 11:e0145264. doi: 10.1371/journal.pone.0145264

Conflict of Interest: The author declares that the research was conducted in the absence of any commercial or financial relationships that could be construed as a potential conflict of interest.

Copyright (C) 2020 Shi. This is an open-access article distributed under the terms of the Creative Commons Attribution License (CC BY). The use, distribution or reproduction in other forums is permitted, provided the original author(s) and the copyright owner(s) are credited and that the original publication in this journal is cited, in accordance with accepted academic practice. No use, distribution or reproduction is permitted which does not comply with these terms. 